\title{
Impact of the Recent Changes in the Pharmacy Remuneration System in Portugal (2010-2014) - Moving from Paper to Reality
}

\author{
Inês Teixeira ${ }^{1 *}$, José Pedro Guerreiro ${ }^{1}$ and Suzete Costa ${ }^{1,2}$ \\ ${ }^{1}$ Center for Health Evaluation \& Research, National Association of Pharmacies, Portugal \\ ${ }^{2}$ US Farmácia Collaborative Care, National Association of Pharmacies, Portugal
}

\begin{abstract}
Objective: The pharmacies and wholesalers' remuneration system for the provision of medicines in Portugal went under structural changes with the Memorandum of Understanding in 2011, which intensified the degree of public pharmaceutical expenditure reduction requirements, in exchange for the financial international assistance. The objectives of the present study were: to provide an overview of the changes, its impact for pharmacies and recent advances towards a more comprehensive system.
\end{abstract}

Methods: Literature review and identification of changes; market analysis and distribution margins were computed using two nationwide databases with representative pharmaceutical dispensing data from ambulatory care; impact of changes and implications for the sector and pharmacies was accessed. Statistical analysis was performed using Statistical Analysis Software (SAS), Guide v4.1.

Results: The fixed linear remuneration system was replaced in 2012 by a regressive mark-up and minor fees system, per price range, determining the greatest modification to the distribution remuneration system during the last decades. An adjustment was made in 2014.

The pharmaceutical market and the National Health System expenditure were reduced by 876 and 494 million euros, respectively, over the past four years. The loss of pharmacy and wholesaler remuneration was 322.8 million euros, higher than the established objective of 50 million euros.

Conclusion: Policy changes, reinforced with the Memorandum of Understanding, caused a large reduction in the remuneration of pharmacies, directly through cuts in margins and indirectly through decreases in prices. Several studies, published in the meantime, support the difficulties for the sector sustainability.

Keywords: Community pharmacy; Pharmaceutical policy; Remuneration system; Portugal; Economic crisis.

Abbreviations: ANF: National Association of Pharmacies; CEFAR: Centre for Health Evaluation \& Research; ECB: European Central Bank; EFP: Ex-Factory Price; EU: European Union; FIP: International Pharmaceutical Federation; GDP: Gross Domestic Product; HMR: Health Market Research; IMF: International Monetary Fund; INFARMED: National Authority of Medicines and Health Products; INN: International Non-proprietary Name; MoU: Memorandum of Understanding; NHS: National Health System; SAS: Statistical Analysis Software, SICMED: Medicines Consumption Information System; QoL: Quality of Life; UK: United Kingdom; VAT: Value Added Tax.

\section{Introduction}

The economic crisis in Portugal, associated with the global financial crisis, resulted in a financial assistance request in 2011 to the European Union (EU), the European Central Bank (ECB) and the International Monetary Fund (IMF). In May 2011 [1], the Portuguese Government and the International Authorities signed the Memorandum of Understanding (MoU) which intensified the degree of health expenditure reduction requirements, namely on the public pharmaceutical spending, to $1.25 \%$ of the Gross Domestic Product (GDP) in 2012 and to about $1 \%$ in 2013 [2]. The aim was to improve efficiency and effectiveness in the health care system, inducing a more rational use of services and control of expenditures. Nevertheless, the reduction in healthcare costs was achieved largely via the reduction of public spending on medicines, mainly in the ambulatory care [3].

In fact, legislation changes in the pharmaceutical sector in Portugal comprised several measures over the last years, such as, changes to the external reference pricing, decreases in medicine prices, including generics, International Non-proprietary Name (INN) prescribing, compulsory electronic prescribing, prescribing guidelines and monitoring of prescribing indicators.

The austerity measures also included the structural change of the pharmacies and wholesalers (distribution) remuneration system for the provision of medicines in Portugal. It was determined in the MoU that the new system should ensure lower profits for the sector, with a contribution of at least 50 million euros to the reduction in public spending on pharmaceuticals and that it should be important to monitor the impact of such legal changes [4].

The MoU also established that if the new system of profit margin calculation would not produce the expected savings, an average rebate (pay-back) contribution would be introduced to be monthly collected by the Government, although outlining the importance of preserving the profitability of small pharmacies in remote areas with low turnover.

*Corresponding author: Inês Teixeira, Center for Health Evaluation \& Research, National Association of Pharmacies, Portugal, Tel: +351213400795 E-mail: ines.teixeira@anf.pt

Received August 09, 2018; Accepted August 31, 2018; Published September 07, 2018

Citation: Teixeira I, Guerreiro JP, Costa S (2018) Impact of the Recent Changes in the Pharmacy Remuneration System in Portugal (2010-2014) - Moving from Paper to Reality. Pharmacoeconomics 3: 117. doi:10.4172/2472-1042.1000117

Copyright: $\odot 2018$ Teixeira l, et al. This is an open-access article distributed under the terms of the Creative Commons Attribution License, which permits unrestricted use, distribution, and reproduction in any medium, provided the original author and source are credited. 
The legislation regulating pharmacies included price reductions and changes in the remuneration system for the provision of medicines, as well as changes in the operating hours (free opening hours with minimum schedule per week), ownership (since 2007 the ownership of pharmacies is no longer restricted to pharmacists, however with some restrictions), staff requirements, stock management, parallel trade and generic substitution with mandatory INN prescription (besides the removal of administrative and legal hurdles to entry of generics) [5].

In the current national context, the objective of the present study is to provide an overview of the reforms in the pharmacies and wholesalers margins' system, to provide evidence of the economic impact for distribution stakeholders (between 2010 and 2014) and to contribute to the discussion of recent advances towards a more comprehensive remuneration system of the community pharmacy in Portugal.

\section{Methods}

This study was conducted comprising three main components: a review of related literature, including published legislation and research papers about the sector in Portugal; a pharmaceutical market and margins analysis; and a comparison of actual margin profit with simulated profit should changes had not occurred, as well as implications for the sector.

Literature review of the updates to the Memorandum of Understanding (European Commission reviews of the Economic Adjustment Programme for Portugal) and of the national published legislation (Diário da Républica), with identification of changes, and studies research (evidence) about the sector in Portugal were accessed (literature review was based on a thorough search for journal articles and abstracts in Medline and relevant grey literature, concerning pharmaceutical policy, community pharmacy, remuneration and economic crisis, mostly in Portugal).

Analysis of pharmaceutical market and of margins of pharmacies and wholesalers was conducted using data retrieved from SICMED (Medicines Consumption Information System) and hmR (Health Market Research) pharmacy sales information systems. These are nationwide databases with representative country and regional estimates of drug dispensing data from ambulatory care, based on sellout sample data from $86 \%$ of the universe of pharmacies in Portugal. This data was linked to other administrative databases containing information about drug prices and reimbursement (SIFARMA ${ }^{\circ}$ and the national dictionary of INFARMED - the National Authority of Medicines and Health Products), as well as to the database of reimbursed prescriptions (DTC database).

Inclusion criteria comprised all medicines dispensed and reimbursed by the National Health System (NHS) which are regulated to have a maximum remuneration margin for pharmacies and wholesalers and which exclude non-prescription medicines not reimbursed by the NHS. Data was collected on a monthly basis and summarized by year. The analysis was conducted for the period of 2010-2014.

Primary outcome measures include the total pharmaceutical market and the NHS pharmaceutical expenditure, the pharmacy and wholesaler margin for the provision of reimbursed medicines, average price per package and the average margin per reimbursed package for pharmacies and wholesalers, in euros. Absolute and relative trend of the estimates was evaluated for the period of analysis. The impact of changes in the remuneration system for the pharmacies and wholesalers was estimated comparing the difference between the real margin turnover of pharmacies and the wholesalers to a simulated turnover calculated using the remuneration system before the changes occurred. Statistical analysis was performed using Statistical Analysis Software (SAS), Guide v4.1.

\section{Results}

The Portuguese remuneration system of the distribution sector for the provision of medicines consisted of a fixed linear system since the 90s. It had established a maximum margin for all pharmaceuticals, with the exception for non-prescription medicines not reimbursed by the NHS, based on a constant per cent mark-up of the price: $20 \%$ of the price retail without VAT (Value Added Tax) for pharmacies and 8\% for wholesalers [6].

The MoU, signed in exchange for the financial assistance, determined the most significant reform of the remuneration system during the last decades, by revising the profit margin to a regressive mark-up and a flat fee which, according to the MoU, had to be «on the basis of the experience in other Member States». In accordance, the Portuguese Government published legislation (Decree-law no. $112 / 2011$, November $29^{\text {th }}$ ) to implement the new system and the fixed linear remuneration system was replaced, in January 2012, by a regressive mark-up based on a percentage of the medicine ex-factory price and a progressive yet minor fee system per package (dispensing fee). The remuneration comprised different mark-up and fees per exfactory price range aiming at encouraging the consumption of less expensive pharmaceuticals, as determined in the MoU (Figure 1). The new remuneration system contained no fee in the lowest price level (just a variable mark-up) and no variable mark-up in the highest price level (Appendix A).

In April 2014 (Decree-law no. 19/2014, February $5^{\text {th }}$ ), an adjustment was made to the system to support the sustainability of access to medicines and to prevent distortions in the provision of cheaper medicines. A new change to the distribution remuneration was implemented, based on assumptions of neutrality to the NHS expenditure, with adjustments in the values of the mark-up and fees (which resulted in a remuneration of $20 \%$ mark-up and $80 \%$ fixed fee per package dispensed, on average - Appendix A). The adjustment also included adding a small fee in the lowest price range to prevent future severe remuneration losses caused by both administrative and industryled price reductions, as well as adding a small mark-up in the highest

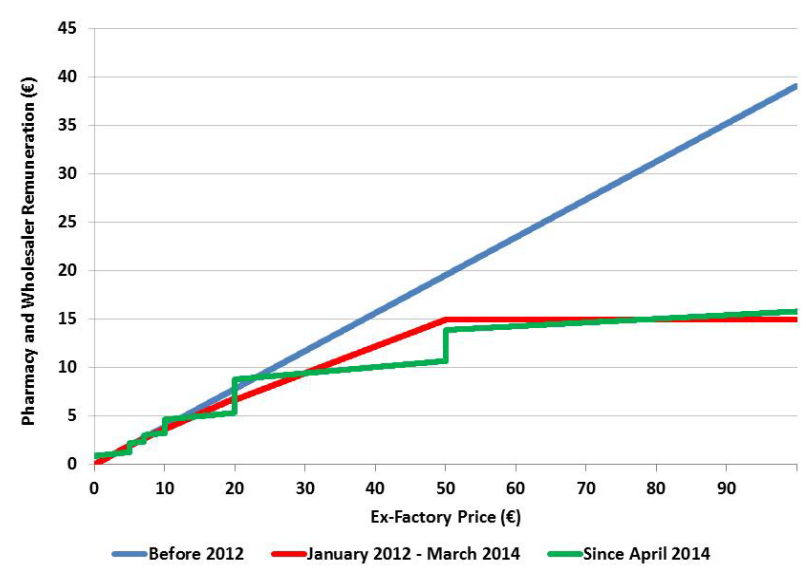

Figure 1: Changes in the distribution (Pharmacy + Wholesaler) remuneration system with medicines sales per ex-factory price.

Source: adapted from legislation (Decree-Law No. 29/90, January $13^{\text {th }}$; DecreeLaw No. 112/2011, November 29 ${ }^{\text {th }}$; Decree-Law No. 19/2014, February $5^{\text {th }}$ ) 
price range to acknowledge the higher costs of purchasing upfront and stocking high-cost medicines. The new legislation also included the intention of creating incentives for pharmacies to dispense generic medicines.

In July 2014, the Ministry of Health and the National Association of Pharmacies (ANF) signed an Agreement which included, for the first time, an innovative clause on the provision of public health interventions in community pharmacies (e.g. diabetes, medication adherence and management, flu immunization, needle exchange and therapeutic substitution) [7,8]. Most of these services, beyond the provision of medicines, had been provided for free in pharmacies for more than 25 years as a voluntary contribution to society as part of their public health role under the former fixed linear remuneration system for the provision of medicines [9]. This Agreement foresees payment if interventions are proven to be effective and cost-effective. In Portugal there was, until this agreement, no NHS reimbursement for the provision of pharmacy services, despite being one of the countries that provides a broader range of such services [10].

The Agreement also determined the contribution of pharmacies to the increase of generic medicines dispensing and associated savings, because there is evidence that the mark-ups schemes based on the price of medicines for remunerating pharmacies create a disincentive to substitute a more expensive medicine by a generic [11]. Legislation on generic incentives for pharmacies was published thereafter (DecreeLaw No. 62/2016, September $12^{\text {th }}$ ).

In addition to the described major measures regulating the pharmacy sector remuneration and the following changes (Table 1), several other policies were implemented to reduce the price of pharmaceuticals: such as changes to the external reference pricing through a regular annual revision to achieve cost savings, and enacting legislation which automatically reduces medicines prices by $50 \%$ when patent expires (generic medicines) [4]. To contribute to the overall decrease of the pharmaceutical expenditure, further actions were implemented, such as INN prescribing, compulsory electronic prescribing, prescribing guidelines and better monitoring of prescribing indicators. The sixth review of the MoU [12] introduced a target for the generics market share in total NHS reimbursed medicines of $45 \%$ in 2013 and $60 \%$ in 2014 (volume in units).

Analysing drug consumption data in ambulatory care between January 2010 and December 2014, it was observed a reduction of 876 million euros (-25.1\%) in the total market value and a cut of 494 million euros in the NHS pharmaceutical ambulatory expenditure (SICMED/hmR databases). Almost half of the market value reduction (408 million euros) was achieved already in 2011, that is to say, even before the implementation of these policies, as a result from changes introduced on the pricing and reimbursement system in ambulatory care in 2010. In previous years (2005-2010) Portuguese pharmacies had already experienced the effect of six successive price cuts, imposed by legislation, which resulted in a loss of their remuneration. In the following years, the downward trend continued, as a result of the policy guidelines from the $\mathrm{MoU}$ and the national implementation of the adjustment program. The quantities purchased were relatively stable along the same period, with a $2.7 \%$ reduction in 2014 compared with 2010.

The loss of pharmacy and wholesaler remuneration was 322.8 million euros ( $37 \%$ of the overall market reduction) in the same period (2010-2014), six times higher than the established goal of 50 million euros in the MoU (Table 2).

Therefore, there was no need for the national Authorities to implement the rebate contribution foreseen for the case of not accomplishing the expected savings and the measure was withdrawn from the MoU update in December 2012 [12]. Furthermore, according to Barros et al, the pharmacies margins reduction exceeded the target already in the first year [13]. The study also concluded that all geographic regions of the country had been affected, with no distinction of small pharmacies located in remote areas with low turnover.

Between 2010 and 2014 there was a reduction in the distribution remuneration of 1.23 euros per reimbursed package dispensed: -0.90 euros for pharmacy and -0.33 euros for wholesaler (Table 3 ). This reduction effort was shared almost equally by pharmacies and wholesalers $(-42.1 \%$ and $-39.8 \%$ respectively, from 2010 to 2014$)$.

\begin{tabular}{|c|c|c|}
\hline MoU Measures (updates) & Actions & Status \\
\hline $\begin{array}{l}\text { Change the calculation of profit margin into a regressive mark- } \\
\text { up and a flat fee for pharmacies and wholesalers }\end{array}$ & $\begin{array}{l}\text { Implementation of the reform with a new remuneration } \\
\text { system }\end{array}$ & $\begin{array}{c}\text { Observed: } \\
\text { Decree-law 112/2011 } \\
\text { (introduced } 1^{\text {st }} \text { January 2012) }\end{array}$ \\
\hline $\begin{array}{l}\text { Pay-back if the new profit margin system will not produce the } \\
\text { expected savings }\end{array}$ & None (not necessary) & Withdrawn \\
\hline $\begin{array}{l}\text { Change the calculation of profit margin for pharmacies and } \\
\text { wholesalers }\end{array}$ & Adjustment of the new remuneration system & $\begin{array}{c}\text { Observed: } \\
\text { Decree-law 19/2014 } \\
\text { (introduced } 1^{\text {st }} \text { April 2014) }\end{array}$ \\
\hline Implement the new legislation regulating pharmacies & $\begin{array}{l}\text { Changed previous decrees on opening times, ownership, } \\
\text { staff requirements, stock management and parallel trade, } \\
\text { generic substitution etc. }\end{array}$ & $\begin{array}{c}\text { Observed: } \\
\text { Decree-Law } 171 / 2012 \text { and Decree-Law } \\
172 / 2012\end{array}$ \\
\hline $\begin{array}{l}\text { Creating incentives for generic medicines dispensing for } \\
\text { pharmacies }\end{array}$ & $\begin{array}{l}\text { Published legislation and an Agreement signed between } \\
\text { the Ministry of Health and the National Associations of } \\
\text { Pharmacies }\end{array}$ & $\begin{array}{l}\text { Decree-law } 19 / 2014 \text { and } \\
\text { Order } 18-\mathrm{A} / 2015 \\
\text { (not put in practice) }\end{array}$ \\
\hline
\end{tabular}

Table 1: Summary of the major measures and legislation concerning the pharmacy sector remuneration

\begin{tabular}{|c|c|c|}
\hline Year & MoU Established Target & Observed margin reductions \\
\hline 2011 & & -97.5 Million euros \\
\hline 2012 & -50.0 Million euros & -187.6 Million euros \\
\hline 2013 & & -28.8 Million euros \\
\hline 2014 & & -8.9 Million euros \\
\hline Total & -50.0 Million euros & -322.8 Million euros \\
\hline
\end{tabular}

Table 2: Total distribution margin reduction with medicines dispensing (2010-2014) - adjustment program objective versus real data effect 
Citation: Teixeira I, Guerreiro JP, Costa S (2018) Impact of the Recent Changes in the Pharmacy Remuneration System in Portugal (2010-2014) Moving from Paper to Reality. Pharmacoeconomics 3: 117. doi:10.4172/2472-1042.1000117

Page 4 of 7

\begin{tabular}{c|c|c|c|c|c|c|}
\multirow{2}{*}{ Year } & \multicolumn{2}{|c|}{ Average margin per reimbursed package dispensed in } & \multicolumn{2}{c|}{$\begin{array}{c}\text { Annual margin reduction per reimbursed package dispensed in } € \text { (and in \% of } \\
\text { total effect) }\end{array}$} \\
\cline { 2 - 6 } & Pharmacies & Wholesalers & Total Distribution & Pharmacies & Wholesalers \\
\hline 2010 & $2.14 €$ & $0.83 €$ & $2.97 €$ & - & - \\
\hline 2011 & $1.78 €$ & $0.71 €$ & $2.49 €$ & $-0.36 €(40.0 \%)$ & $-0.12 €(36.4 \%)$ \\
\hline 2012 & $1.37 €$ & $0.56 €$ & $1.93 €$ & $-0.41 €(45.6 \%)$ & $-0.15 €(45.5 \%)$ \\
\hline 2013 & $1.28 €$ & $0.52 €$ & $1.80 €$ & $-0.09 €(10.0 \%)$ & $-0.04 €(12.1 \%)$ \\
\hline 2014 & $1.24 €$ & $0.50 €$ & $1.74 €$ & $-0.04 €(4.4 \%)$ & $-0.02 €(6.1 \%)$ \\
\hline Total & - & - & - & $-0.90 €(100 \%)$ & $-0.13 €(10.6 \%)$ \\
\hline
\end{tabular}

Table 3: Average pharmacies and wholesalers margins per reimbursed package dispensed in the NHS market (2010-2014).

On the other hand, the distribution margin reduction per package was higher in 2011 (39.0\% of total margin reduction of 1.23 euros) before the MoU changes, and again accentuated in 2012 (45.5\% of total impact) by the time of the second remuneration system modification, compared with 2013 and 2014.

The estimated difference between the real pharmacy and wholesaler's margins and the simulated margins, had changes in the remuneration system not occurred, was 113.2 million euros, between 2010 and 2014.

Thus, the results were not only a consequence of the direct cuts of the distribution margins after 2012, but of the medicines severe price reductions observed in the ambulatory market since 2010 (there was a cut of about -4.10 euros per package dispensed with NHS reimbursement, between 2010 and 2014), as well. This last effect was due to changes in the Portuguese price and reimbursement system in 2011 followed by patterns of the pharmaceutical market, such as dispensing of more cheaper medicines and price competition in generic prices, less innovative and expensive medicines, and then added to the numerous price reductions measures previously described and implemented with the MoU after 2011.

Regarding the observed trend in the market share of generics, despite the growth from $41.5 \%$ in 2012 to $45.0 \%$ in 2013 (volume in units) from the INN prescribing implementation, the target established in the MoU for 2014, of $60 \%$ of total NHS medicines, was not accomplished. In 2014, the generics market share of $46.6 \%$ (SICMED/hmR databases) was almost stable considering the previous year. Nevertheless, the public (NHS) and private (out-of-pocket) expenditures on generic medicines were highly reduced due to the effect of the substantial price cuts for generics over the last years.

\section{Discussion}

The effects of changes are patent in terms of the challenges across the sector over the last years, based on the literature review of the MoU measures and following updates, on published legislation and, finally, on studies about the pharmaceutical sector in Portugal.

The market analysis results from this study and the simulations to measure the impact of changes and implications for the sector and for the pharmacies are endorsed by international figures and studies published over the years following the MoU which demonstrate the reduction of pharmaceutical market value and distribution margins.

These results are consistent with international studies that include Portugal in the countries with a dramatically decrease in retail pharmaceutical spending, associated with patent expiries of several blockbuster drugs over the last decade, but mainly due to costcontainment policies, particularly, as a consequence of the economic crisis and financial adjustment programme $[11,13,14]$.
Portugal stands out from the OECD countries, in recent years, by the reduction in health spending, especially with medicines, emerging as one of the countries with the highest decrease [15]. Public expenditure on pharmaceuticals dropped by $3.2 \%$ on average across OECD countries between 2009 and 2013, with a particularly large reduction in Portugal $(-11.1 \%)$, followed by Denmark $(-10.4 \%)$ and Iceland $(-9.9 \%)$ [11]. On the other hand, in previous years, between 2000 and 2013, the number of pharmacists per capita had increased in almost all OECD countries, but most rapidly in Portugal, Ireland, Japan, Spain and Hungary.

An international study that analyses the effects of the economic recession in the pharmaceutical policy of several European countries concludes that Portugal is the country with the highest number of implemented measures ( 22 in total of 88 ) between 2009 and 2011, even before the international assistance programme [16]. Additionally the measures were mainly in terms of distribution remuneration changes and margins reduction, and related to price cuts, which led to public expenditure decrease on medicines in the short term, but that could have had a negative impact on the availability of medicines for several reasons such as pharmaceutical companies opting to withdraw products from national lists, as well as financial constraints of pharmacies to acquire and pay upfront for stocking once usually available medicines. Pharmaceutical sales in volume increased moderately in countries except for Portugal and Greece. Nevertheless, it is also noted that the most effective policies are related to the promotion of changes in the prescription and medicines utilisation patterns, even more delayed in terms of effect.

Furthermore, these measures have caused a negative impact especially for pharmacies and wholesalers affected by the double reduction in the remuneration, namely the direct cut of the margin and the indirect effect of successive decreases in prices of medicines [17], which are the main source of remuneration of pharmacies $(77.2 \%$ of the pharmacy market) [18]. Moreover, the average pharmacy has been operating with negative economic profits since 2010 [19], even before the austerity policies associated to international assistance. Additionally, evidence indicates that there is no opportunity to compensate the margin loss with sales from other products, which margins are not regulated [13].

According to the 2017 Portugal Health System Review [20] (page 127): "The continuing trend of declining prices among pharmaceutical products has reduced revenues to pharmacies and wholesalers, as their revenues result from a regressive margin on the price of the product (...) and, as a result, pharmacies have claimed to face difficult economic and financial conditions, including refusals by wholesalers to sell to them due to delays of payment by pharmacies."

It is important to understand the consequences for the network of pharmacies and on patients' access to medicines, particularly in 
the face of evidence of a large number of pharmacies with difficulties in medicines supply and problems of economic and financial order. Shortages and difficulties experienced by patients in obtaining all prescribed medicines were reported. Although acknowledging that shortages have multifactorial causes, these were aggravated in the recession period, as reported by patients [21].

One recent study demonstrates that pharmacies are unprofitable [22], with a sudden drop in the average net result of $82 \%$ between 2010 and 2013 for pharmacies: 40,721 euros to 7,271 euros $(3.1 \%$ and $0.7 \%$ of business volume, respectively); and $19 \%$ of pharmacies $(n=567)$ have a negative result before tax. The negative results occur more frequently in pharmacies with lower turnover, but, globally, reflect difficulties throughout the sector. Another reference to the Portuguese case study states that current estimates suggest that revenues per prescription for pharmacies are below its marginal cost and, so, further price cuts in medicines linked to distribution margins will put the pharmacy network at risk [17]. Additionally, in December 2014, about 16.9\% of all pharmacies in Portugal had an insolvency or a pledge process $(\mathrm{n}=$ 492 , out of 2,915 , data from a national independent business database) [23]. The costs of the first years of negative results were still borne by owners, probably favoured by the fact that the majority of them are still pharmacists with stronger affectionate ties to the pharmacy business and profession which could explain a delayed effect of insolvencies and pledges.

One study from the European Commission stated that the Pharmacies in Portugal had one of the lowest margins in Europe (only surpassed by Romania), before the structural change in the remuneration system [24], in line with other publications [25]. A recent economic study on regulation, efficiency and access to medicines, which reviewed the methodologies for calculating margins (of wholesalers and pharmacies) with the dispensing of medicines in some European countries, building a benchmarking analysis, places Portugal in the group of countries with lower remuneration [26]. The author concludes that the type of remuneration model may have effect on the sustainability of some pharmacies and (negatively) affect the viability of dispensing medicines in more remote areas (rural areas, for example), and that incentives and disincentives to distribution should be monitored and reviewed regularly, with consideration of potential unexpected effects. The regulation of distribution margins has a direct impact on the agents, but also in the industry, with potential consequences for patients' access to the medicines.

Another study from 2012 [27] concludes that difficulties reported had not yet generated relevant access issues, but the existing negative margins per prescription for pharmacies would lead to access problems. Therefore, some austerity measures may potentially influence patients' access to medicines and consequently impact adherence, which will influence health status, especially in patients with chronic diseases [28]. Shortages reported by pharmacies and difficulties reported by patients in obtaining prescribed medicines are also reported in another study [21]. A cross sectional study, undertaken in Portugal (community pharmacy setting) during 2013 [29], to evaluate the perceived effects of the crisis on elderly patient's access to medicines and medical care, and its implications on medicine-taking behaviour, showed that costcontainment measures applied to medicines may impact on adherence and that policy makers should be aware of the long-term consequences of these measures on adherence.

Despite the obvious need for contributions from all public and private sectors in the Portuguese society to lower the pharmaceutical public expenditure, the objective criteria which led to the decision to reduce the remuneration of pharmacies and wholesalers by 50 million euros is not known, nor the European remuneration systems that were meant to guide the change in Portugal as stated in the MoU, nor the impact studies that should normally be performed prior to major legislation changes. The changes also put in evidence the absence of clear and transparent criteria to guide remuneration fair values of pharmacies and wholesalers. Unlike ex-factory prices that have objective criteria in 27 European countries based on a basket of reference countries, wholesalers and pharmacy remunerations across Europe have no known underlying criteria. These are important lessons to learn for future improvements.

The Agreement signed in 2014 determines a system of incentives for pharmacists to dispense generic medicines, subject to evidence of global savings for the NHS and for patients by increasing the generic share. The remuneration was regulated (Decree-Law No. 19/2014, February $5^{\text {th }}$; Order No. 18-A/ 2015, February $2^{\text {nd }}$ ) to share a part of the generated savings with pharmacies to minimize the loss of earnings due to dispensing cheaper medicines, but no significant compensations were paid. Subsequently, new regulation was published and implemented (Decree-Law No 62/2016, September 12 $2^{\text {th }}$ ) with a fixed fee for each package dispensed for cheaper medicines, associated to the contribution of the pharmacy in reducing the reference price, as an incentive for dispensing cheaper medicines. In the legislation it is stated that community pharmacies play a leading role in promoting better and more rational access to medicines (in particular through the use of generics), one of the components of promoting adherence.

The results of a study concerning the impact of margins on generic substitution suggest that pharmacy incentives are crucial to promote generics [30]. There are already numerous solutions in several European countries (Belgium, Switzerland, Italy, France and the United Kingdom) to introduce incentives for pharmacies for dispensing generic, as recommended in international studies [31]. For example, France guarantees pharmacists an equivalent mark-up, while in Switzerland pharmacists receive a fee for generic substitution [11]. The authors of another study conclude that community pharmacists can play an important role in the development of the generic market, noting that the remuneration of pharmacies should not penalize the dispense of cheaper medicines, and should evolve to a fee-forperformance remuneration model rather than a margin dependent on the price of the drug [32]. It is expected that this alignment of incentives could constitute an appropriate measure to promote the use of generic medicines without the worsening of the sustainability and viability of Portuguese pharmacies, as more generics enter the market.

The 2014 Agreement also denotes the value of the role of Pharmacy in the primary health care system in the context of public health interventions, aligning national policies with European trends and recognizing the principle of remuneration for relevant services provided in pharmacies. It was assumed an innovative commitment to sharing risk and gains, by making the continuity and remuneration of services reliant on an independent effectiveness and cost-effectiveness evaluations, following an experimental period in which services are provided free of charge $[7,8]$. This is an important and innovative decision as it applies the same principle of health technology assessment used in the reimbursement of medicines to the reimbursement of public health interventions.

Mossialos et al. [33] conclude that there is an emerging consensus among academics, professional organization and policymakers that community pharmacists should have a broader role, by promoting the safe, effective and efficient use of medicines (especially regarding 
patients with multiple chronic conditions), contributing also to the improvement of health outcomes, mainly by reducing side effects and improving compliance, while enhancing integrated primary care delivery across the health system. However, despite their considerable training, community pharmacists are the only health professionals who are not primarily rewarded for delivering health care.

There is also international evidence of improvements in efficiency and results of health systems associated with services. A recent study that evaluated the effectiveness and cost-effectiveness of a service (New Medicines Service) in place in $90 \%$ of community pharmacies in the UK [34], to improve patients' adherence to new medicines found better health outcomes and lower costs for the NHS, and that its benefits could be further improved through better integration with primary care.

A study in Portuguese pharmacies [35] states that there is a clear opportunity for improving service management by optimizing dispensing, since this represents the most relevant cost, and that low cost pharmaceutical care services should be promoted as additional revenue paths. Another study [36] estimated that current community pharmacies services in Portugal provide a gain in Quality of Life (QoL) of $8.3 \%$ and an economic value of 879.6 million euros, including 342.1 million euros in non-remunerated pharmaceutical services and 448.1 million euros in avoided expense with health resource consumption. Authors conclude that an increase range of services including a greater integration in primary and secondary care, among other transversal services, may add further social and economic value to the society.

According to Barros PP et al. [27] the economic model for pharmacies should lead to a more efficient distribution of medicines while safeguarding both the economic sustainability of pharmacies and the impact on patients, through cost reductions, remunerating for additional added value services and the exploring how to best adjust current regressive margins and fees per item dispensed.

\section{Conclusion}

To conclude, even before the implementation of the policies in Portugal with the international assistance programme, several changes were introduced on the pricing and reimbursement system that lead to a high reduction of the market and public expenditure on medicines in ambulatory care in 2011. In the following years, despite the relatively stable units purchase, that trend continued as a result of the guidelines from the MoU and the national implementation of the adjustment program.

The pharmacies and wholesaler's remuneration, which had already been reduced due to indirectly decrease in prices of medicines, was again reduced by directly cuts in margins, causing additional difficulties for the sustainability of the sector, evidenced already in several published studies. As prices of medicines will continue to experience a downward pressure, a modification in pharmacies' remuneration for their dispensing should occur to avoid disruption in the existing network [17].

Discussion should be centred on a more comprehensive remuneration system since the important role of pharmacists in providing public health interventions which has changed over the years [37]: still the main role being the provision of medicines in community pharmacies, pharmacists are moving to service oriented providing direct care to patients, integrated in the primary health care system. A more comprehensive and balanced remuneration system should include a fair combination of mark-ups, dispensing and professional fees to remunerate the most important role of pharmacies in ensuring equitable patient access to a reliable, safe and effective medicines supply network; incentives for efficiency and quality; and payment for public health and other relevant pharmacy services, as reported in the study on international remuneration systems by International Pharmaceutical Federation (FIP) [38].

Finally, more research is needed to better inform pharmaceutical and public health policies.

\section{Declarations Sections}

\section{Ethics}

\section{Not applicable}

\section{Competing interests}

All three authors were researchers employed at the Centre for Health Evaluation \& Research (CEFAR) of the National Association of Pharmacies (ANF) when the study was conducted. ANF commissioned this research to CEFAR but had no role in design, collection, analysis, interpretation of data; writing of the manuscript; nor in the decision to submit the manuscript for publication. The opinions, findings, conclusions or recommendations expressed in this paper are of the authors and do not reflect necessary the views of ANF.

\section{Authors' Contributions}

IT was responsible for the conduct of the study and study design, participated in data extraction and statistical analysis, and drafted the manuscript. JPG participated in data extraction and statistical analysis, study design and revised the manuscript. SC participated in collection of additional literature, study design and revised the manuscript. All authors read and approved the final manuscript.

\section{Availability of Data and Materials}

Some restrictions will apply. Data from the two databases are available for researchers upon request to National Association of Pharmacies.

\section{Acknowledgement}

The authors gratefully acknowledge all Portuguese pharmacies that voluntarily provide sales data to the National Association of Pharmacies (ANF), which feeds the databases with representative pharmaceutical dispensing data from ambulatory care and thank ANF for granting unrestricted access to these databases. Authors are also grateful for the useful comments and suggestions of the participants at the $14^{\text {th }}$ Portuguese National Conference on Health Economics (Lisbon, October 2015) to an oral communication based on a previous draft of this research.

\section{References}

1. Barros PP (2012) Health policy reform in tough times: The case of Portugal. Health Policy 106: 17-22.

2. Portugal-Memorandum of understanding on specific economic policy conditionality. 17 May 2011: 1-34

3. Sakellarides C, Castelo BL, Barbosa P, Azevedo H (2014) The impact of the financial crisis on the health system and health in Portugal. Eur Observatory of Health System Policies 1-56.

4. European Commission-Directorate General Economic and Financial Affairs (2012) The Economic Adjustment Programme for Portugal. Third Review Winter 2011/2012. European Economy, Occasional p: 95.

5. European Commission-Directorate General Economic and Financial Affairs (2012) The Economic Adjustment Programme for Portugal. Fifth Review Summer 2012. European Economy, Occasional p: 117.

6. Teixeira I, Vieira I (2008) PPRI Pharma Profile Portugal 2008. Pharmaceutica Pricing and Reimbursement Information; Commissioned by the European Commission, Directorate-General Health and Consumer Protection and Austrian Federal Ministry of Health, Family and Youth. P: 86. 
Citation: Teixeira I, Guerreiro JP, Costa S (2018) Impact of the Recent Changes in the Pharmacy Remuneration System in Portugal (2010-2014) Moving from Paper to Reality. Pharmacoeconomics 3: 117. doi:10.4172/2472-1042.1000117

7. Ministério da Saúde (2014) Acordo entre o Ministério da Saúde e a Associação Nacional das Farmácias sobre a implementação de programas de Saúde Pública [Internet]. Lisbon: INFARMED.

8. Martins A, Queirós S (2014) Acordo para implementação de Programas de Saúde Pública nas Farmácias Portuguesas. Revista Portuguesa Farmacoterapia 6: 234-235.

9. Costa S, Santos C, Silveira J (2006) Community pharmacy services in Portugal. Ann Pharmacother 40: 2228-2234.

10. Kanavos P, Schurer W, Vogler S (2011) The Pharmaceutical Distribution Chain in the European Union: Structure and Impact on Pharmaceutical Prices 1-120.

11. OECD (2015) Health at a glance 2015: OECD Indicators

12. European Commission-Directorate General Economic and Financial Affairs (2012) The Economic Adjustment Programme for Portugal. Sixth Review Autumn 2012. European Economy, Occasional p: 124.

13. Barros PP, Martins B, Moura A (2012) Changing Margins in Pharmaceutical Distribution: Who Benefits from the New Slicing of the Pie? Value in Health 15: A321.

14. Teixeira I, Mendes Z, Guerreiro JP, Costa S (2013) Troika in Portugal: Pharmaceutical Sector from Paper to Reality. Value in Health 16: A456.

15. Belloni A, Morgan D, Paris V (2016) Pharmaceutical expenditure and policies: past trends and future challenges. Paris: OECD, p: 87.

16. Leopold C, Mantel TAK, Vogler S, Valkova S, Joncheere DK, et al. (2014) Effect of the economic recession on pharmaceutical policy and medicine sales in eight European countries. Bull World Health Organ 92: 630-40.

17. Barros PP (2013) Chapter 5. Lessons from the European Union. Case Study 2: Changes in the Health Sector under Economic Crisis and Financial Rescue: Portugal. In: Hou X, Veléni EV, Yazbeck AS, lunes RF, Smith O. Learning from Economic Downturns: How to Better Assess, Track.

18. Martins L, Queirós S (2015) Competition among pharmacies and the typology of services delivered: The Portuguese case. Health Policy 119: 640-647.

19. Barros PP, Martins B, Moura A (2012) The rocky road to market equilibrium Price regulation and entry liberalization in the Portuguese retail pharmacy. Value in Health 15: A321.

20. Simões JA, Augusto GF, Fronteira I, Hernández-Quevedo C (2017) Health System in Transition - Portugal Health System Review. European Observatory on Health Systems and Policies, World Health Organization.

21. Romano S, Godinho A, Mendes Z, Costa S (2015) Medicines Shortages in Portuguese Community Pharmacies and Access Limitations Reported by Patients. Poster session presented at: $75^{\text {th }}$ FIP World Congress of Pharmacy and Pharmaceutical Sciences; Düsseldorf, Germany.

22. Antão A, Grenha C (2015) Estudo Económico/Financeiro - Sector das Farmácias em Portugal. Universidade de Aveiro, Oliveira, Reis Associados SROC, Lda.
23. Portuguese Observatory of Health Systems (2015) Relatório de Primavera 2015 - Acesso aos cuidados de saúde. Um direito em risco? P: 86.

24. Carone G, Schwierz C, Xavier A (2012) Cost-containment policies in public pharmaceutical spending in the EU.

25. Vinces (2014) El Sistema retributivo de la farmacia Española: Evaluación de Modelos Fallidos y Propuestas Eficaces.

26. Teixeira I (2017) Regulação, Eficiência e Acesso à Saúde e a Medicamentos: Margens de Comercialização em Países Europeus. Instituto de Pesquisa Econômica Aplicada (IPEA). Brasília: Rio de Janeiro.

27. Barros PP, Martins B, Moura A, Teixeira I, Costa S, Queirós S (2012) The Pharmacists' and Patients' Side of Policy Measures in Pharmaceutical Markets: The Effects of Changing Pharmacy Margins. Value in Health 15: A322.

28. Costa FA, Pedro AR, Teixeira I, Bragança F, da Silva JA, et al. (2015) Primary non-adherence in Portugal: findings and implications. Int J Clin Pharm 37: 626635

29. Costa FA, Teixeira I, Duarte-Ramos F, Proenca L, Pedro AR, et al. (2016) Effects of economic recession on elderly patients' perceptions of access to health care and medicines in Portugal. Int J Clin Pharm 39: 104-112.

30. Brekke K, Olmas T, Straume O (2013) Margins and market shares: pharmacy incentives for generic substitution. Eur Econ Review 61: 116-131.

31. Simoens S (2013) Sustainable provision of generic medicines in Europe. KU Leuven.

32. Dylst $P$, Vulto A, Simoens $S$ (2012) How can pharmacist remuneration systems in Europe contribute to generic medicine dispensing? Pharmacy Practice 10 3-8

33. Mossialos E, Courtin E, Naci H, Benrimoj S, Bouvy M, et al. (2015) From "retailers" to health care providers: Transforming the role of community pharmacists in chronic disease management. Health Policy 119 :628-639.

34. Elliott RA, Matthew J Boyd, Justin Waring NB, Mehta R, Chuter A, et al. (2014) Department of Health Policy Research Programme Project 'Understanding and Appraising the New Medicines Service.

35. Gregorio J, Russo G, Lapao L (2015) Pharmaceutical services cost analysis using time-driven activity based costing in a sample of Portuguese community pharmacies. Int J Clin Pharm 37: 403-404.

36. Felix J, Ferreira D, Afonso-Silva M, Gomes MV, Ferreira C, et al. (2017) Socia and Economic Value of Portuguese Community Pharmacies in Health Care. BMC Health Serv Res 17: 606

37. Martins SF, Van Mil JWF, Costa FA (2015) The organizational framework of community pharmacies in Europe. Int J Clin Pharm 37: 896-905.

38. International Pharmaceutical Federation (2015) Sustainability of Pharmacy Services: Advancing Global Health. International overview of remuneration models for community and hospital pharmacy. Executive Summary. The Hague: FIP 


\section{Appendix A}

Distribution Remuneration System per medicine dispensing: January 2012

\begin{tabular}{|c|c|c|c|c|}
\hline $\begin{array}{c}\text { Medicine Ex-Factory } \\
\text { Price (EFP) }\end{array}$ & \multicolumn{2}{|c|}{ Wholesaler Remuneration } & \multicolumn{2}{c|}{ Pharmacy Remuneration } \\
\cline { 2 - 5 } & Margin \% (EFP) & Fee $€$ & Margin \% (EFP) & Fee $€$ \\
\hline$\leq € 5.00$ & $11.20 \%$ & - & $27.90 \%$ & - \\
\hline$€ 5.01-€ 7.00$ & $10.85 \%$ & - & $25.70 \%$ & $€ 0.11$ \\
\hline$€ 7.01-€ 10.00$ & $10.60 \%$ & - & $24.40 \%$ & $€ 0.20$ \\
\hline$€ 10.01-€ 20.00$ & $10.00 \%$ & - & $21.90 \%$ & $€ 0.45$ \\
\hline$€ 20.01-€ 50.00$ & $9.20 \%$ & - & $18.40 \%$ & $€ 1.15$ \\
\hline$>€ 50.00$ & - & $€ 4.60$ & - & $€ 10.35$ \\
\hline
\end{tabular}

Source: adapted from legislation (Decree-Law No. 112/2011, November $29^{\text {th }}$ )

Distribution Remuneration System per medicine dispensing: April 2014 adjustment

\begin{tabular}{|c|c|c|c|c|}
\hline $\begin{array}{c}\text { Medicine Ex-Factory } \\
\text { Price (EFP) }\end{array}$ & \multicolumn{2}{|c|}{ Wholesaler Remuneration } & \multicolumn{2}{c|}{ Pharmacy Remuneration } \\
\cline { 2 - 5 } & Margin \% (EFP) & Fee $€$ & Margin \% (EFP) & Fee $\boldsymbol{\epsilon}$ \\
\hline$\leq € 5.00$ & $2.24 \%$ & $€ 0.25$ & $5.58 \%$ & $€ 0.63$ \\
\hline$€ 5.01-€ 7.00$ & $2.17 \%$ & $€ 0.52$ & $5.51 \%$ & $€ 1.31$ \\
\hline$€ .01-€ 10.00$ & $2.12 \%$ & $€ 0.71$ & $5.36 \%$ & $€ 1.79$ \\
\hline$€ 10.01-€ 20.00$ & $2.00 \%$ & $€ 1.12$ & $5.05 \%$ & $€ 2.80$ \\
\hline$€ 20.01-€ 50.00$ & $1.84 \%$ & $€ 2.20$ & $4.49 \%$ & $€ 5.32$ \\
\hline$>€ 50.00$ & $1.18 \%$ & $€ 3.68$ & $2.66 \%$ & $€ 8.28$ \\
\hline
\end{tabular}

Source: adapted from legislation (Decree-Law No. 19/2014, February $5^{\text {th }}$ ) 